\title{
Identification of the invariant chain (CD74) as an angiotensin AGTR1-interacting protein
}

\author{
Márta Szaszák*, Hung-Dar Chen*, Hao-Chia Chen, Albert Baukal, László Hunyady ${ }^{\mathbf{1}}$ and Kevin J Catt \\ Section on Hormonal Regulation, Endocrinology and Reproduction Research Branch, Program in Developmental Endocrinology and Genetics, Eunice Kennedy \\ Shriver National Institute of Child Health and Human Development, National Institutes of Health, Bethesda, Maryland 20892-4510, USA \\ ${ }^{1}$ Department of Physiology, Semmelweis University, H-1444 Budapest, Hungary \\ (Correspondence should be addressed to K J Catt; Email: cattk@mail.nih.gov) \\ *(M Szaszák and H-D Chen contributed equally to this work)
}

\begin{abstract}
Little is known about the protein-protein interactions that regulate the trafficking of the angiotensin II type I receptor (AGTR1) through the biosynthetic pathway. The membraneproximal region of the cytoplasmic tail of the AGTR 1 has been identified by site-directed mutagenesis studies as an essential site for normal AGTR1 folding and surface expression. Based on yeast two-hybrid screening of a human kidney cDNA library with the AGTR1 carboxyl-terminal tail as a bait, we identified the invariant chain (CD74) as a novel interacting protein. This association was confirmed by co-immunoprecipitation and co-localization studies. The binding site for CD74 on the AGTR1 carboxyl-terminal tail was localized to a site previously
\end{abstract}

identified as important for the exit of the AGTR1 from the endoplasmic reticulum (ER), and conserved in many G proteincoupled receptors. Transient co-expression of CD74 with the AGTR1 in CHO-K1 cells consistently reduced the AGTR1 density at the cell surface. Furthermore, the interaction of CD74 with the carboxyl-terminal tail of the AGTR1 caused its retention in the ER and promoted its proteasomal degradation. These observations indicate that CD74 and the AGTR1 become associated in the early biosynthetic pathway, and that CD74 is a negative regulator of AGTR1 expression.

Journal of Endocrinology (2008) 199, 165-176

\section{Introduction}

The angiotensin II type I receptor (AGTR1) is the primary effector in the physiological actions of the octapeptide hormone, angiotensin II (AngII), on blood pressure regulation, and salt/water balance. The AGTR1 is also involved in the pathogenesis of renal diseases and several cardiovascular disorders, including hypertension, cardiac hypertrophy, and atherosclerosis, and has been implicated in the Marfan syndrome and cancer. In addition to its classical target tissues, local AngII formation has important physiological roles in a number of other cell types, including immune cells (Hunyady \& Catt 2006). Binding of AngII to AGTR1s initiates conformational changes that lead to an activation of $\mathrm{G}$ proteins, predominantly Gq11, and several signaling pathways including stimulation of phospholipase C (PLC), $\mathrm{Ca}^{2+}$ signal generation, activation of protein kinase $\mathrm{C}$ isoforms and small $\mathrm{G}$ proteins, stimulation of receptor and non-receptor tyrosine kinases, and activation of mitogen-activated protein kinases (MAPKs; de Gasparo et al. 2000, Hunyady \& Catt 2006). In parallel with these signaling events, AngII also causes internalization of the AGTR1 (Thomas 1999). These diverse signaling pathways, and the intracellular trafficking of the receptors, are modulated by a variety of protein-protein interactions.
The carboxyl-terminal tail of the AGTR1 is recognized as the main site of such interactions, and site-directed mutagenesis studies have identified motifs that are important in receptor signaling (Shibata et al. 1996, Oliveira et al. 2007), internalization (Hunyady et al. 1994), trafficking (Anborgh et al. 2000, Duvernay et al. 2004), and desensitization (Smith et al. 1998). However, there is a dearth of information about the direct protein-protein interactions of the carboxyl-terminal tail of the AGTR1 and the several proteins that bind to this region of the receptor. These include PLC $\gamma$ (Venema et al. 1998), JAK2 (Ali et al. 1997), AGTR1-interacting proteins termed ATRAP (also known as AGTRAP; Daviet et al. 1999, Guo et al. 2003), as well as thimet oligopeptidase 1 (EP24.15; Shivakumar et al. 2005), GDP/GTP exchange factor-like protein (Guo et al. 2004), RAB5A (Seachrist et al. 2002), caveolin (Wyse et al. 2003), and $\beta$-arrestin (Qian et al. 2001). In searching for other interacting proteins with specific regulatory functions, we utilized yeast two-hybrid screening with the AGTR1 carboxyl-terminal tail as bait, and observed that the invariant chain (CD74) is a novel interacting protein for the AGTR1 carboxyl terminus.

CD74 is a type II transmembrane protein that is primarily expressed in antigen-presenting cells, and acts as a chaperone for the major histocompatibility complex (MHC) class II 
molecules. Shortly after synthesis, CD74 forms trimers and associates with the MHC class II $\alpha$ and $-\beta$ heterodimers in the ER, forming a nanomer complex. This association prevents peptide binding in the ER. The fully assembled MHC class II-CD74 complex exits the ER, transits the Golgi, and is directed to the endosomal-lysosomal compartments. There, CD74 is degraded and released from MHC class II molecules, which form dimers that bind the antigenic peptides and traffic to the cell surface for presentation to the T-lymphocytes (Lamb et al. 1991, Lamb \& Cresswell 1992). In addition to its location in the ER and in lysosomes, $2-5 \%$ of cellular CD74 is expressed at the cell surface, where it acts as a high-affinity binding protein for the macrophage migration inhibitory factor (MIF; Leng et al. 2003). MIF binds to the extracellular domain of CD74 and is required for the activation of MAPK cascades and cell proliferation, as well as PTGER 2 production (Lue et al. 2006). The CD74 protein is also expressed independently of MHC class II expression in a number of specific cell types (Momburg et al. 1986, Badve et al. 2002).

Our studies indicate that CD74 associates with the AGTR1 early in the biosynthetic pathway, and impedes its intracellular trafficking. Consequently, co-expression of CD74 causes AGTR1 accumulation in the ER, and its proteasomal degradation via the ER-associated pathway.

\section{Materials and Methods}

\section{Materials}

The cDNA of the human AGTR1, used for yeast two-hybrid screen, was provided by Dr Bergsma (SmithKline Beecham Pharmaceuticals). The cDNA of the rat vascular smooth muscle AGTR1A-receptor, used for co-immunoprecipitation, binding, internalization assays, and confocal microscopy studies, was provided by Dr Bernstein (Emory University, Atlanta, GA, USA). The cDNA of the human CD74 was provided by Dr Eric O Long (NIAID, Bethesda, MD, USA). Anti-HA.11 monoclonal antibody was from Covance (Berkeley, CA, USA). Anti-Xpress monoclonal antibody was from Invitrogen, anti-calreticulin polyclonal antibody was from Abcam (Cambridge, MA, USA), horseradish peroxidaseconjugated goat anti-mouse antibody was from KPL (Gaithersburg, MD, USA), Alexa 594-conjugated goat antimouse IgG and fluorescein isothiocyanate (FITC)-conjugated goat anti-rabbit IgG were from Molecular Probes (Eugene, OR, USA), protease inhibitor cocktail set III and MG-132 was from Calbiochem (La Jolla, CA, USA), and leupeptin was from Bachem (Torrance, CA, USA). Unless otherwise stated, all other chemicals and reagents were from Sigma. Chinese hamster ovary (CHO)-K1 and human embryonic kidney (HEK) 293 cells were from ATCC (Manassas, VA, USA) and CHO-K1 Tet-On cells were from Clontech. Human adrenocortical carcinoma cell line, NCI-H295R was from ATCC. pcDNA4/ HisMax C plasmid was from Invitrogen, and pTRE-Tight and pEGFP-C3 plasmids were from Clontech.

\section{Two-hybrid screen}

The cDNA library screening was performed using the MATCHMAKER LexA Two-Hybrid System (Clontech). The mutant human AGTR1 carboxyl terminus (T332D, S335D, and T336D) bait used for the yeast two-hybrid screen contained amino acids 301-359 fused in-frame with the pLexA DNA-binding domain (BD) in vector pGilda. This region of AGTR1 encompassing the entire cytoplasmic carboxyl-terminal segment was synthesized by PCR with restriction sites (EcoR I and Xho I) at $5^{\prime}$ and $3^{\prime}$ ends. The resulting construct pGilda-mhAGTR1 (C) was co-transformed into yeast EGY48 [p8op-lacZ] with a human kidney MATCHMAKER Lex A cDNA library (Clontech) that contained the pB42AD activation domain (AD). From over $9 \times 10^{7}$ primary colonies screened, 46 putative positive colonies were identified. To eliminate duplicate colonies bearing the same $\mathrm{AD} /$ library plasmid, the insert-screening procedure was applied. Plasmids from 13 out of $46 \mathrm{Leu}^{+}$, $\mathrm{LacZ}^{+}$yeast transformant colonies were isolated and the $\mathrm{AD} /$ library inserts amplified by PCR. The PCR products were characterized by digesting with a frequent-cutter restriction enzyme, Hae III, and fragment sizes analyzed by agarose gel electrophoresis. One representative activating plasmid was rescued and the cDNA insert sequenced.

\section{Plasmid constructs, mutagenesis, and transfection}

The green fluorescent protein (GFP)-tagged AGTR1 (AGTR1-GFP) was constructed by linking the cDNA of enhanced green fluorescent protein (EGFP) carboxy terminally to the coding region of the AGTR1 as described earlier (Hunyady et al. 2002). The hemagglutinin epitope (HA)tagged AGTR1 (HA-AGTR1) was amplified by PCR and subcloned into the pTRE-Tight expression vector. CD74 was amplified by PCR and subcloned into the pcDNA4/ HisMax C expression vector. The CD74 N-terminal deletion mutants were constructed by PCR and subcloned into the pcDNA4/HisMax $\mathrm{C}$ vector. The sequences of the mutants were verified by sequencing. CHO-K1 cells were transiently transfected in 24-well plates with the indicated constructs using $12 \mu \mathrm{g} / \mathrm{ml}$ Lipofectamine (Carlsbad, CA, USA) as described previously (Hunyady et al. 1994). For confocal microscopy, cells were grown on glass coverslips and transfected with the indicated constructs using $3 \mu \mathrm{l} / \mathrm{ml}$ FuGENE 6 (Roche Diagnostics). CHO-K1 cells were maintained in $\mathrm{NaHCO}_{3}$-buffered Ham's F-12 medium containing $10 \% \quad(\mathrm{v} / \mathrm{v})$ fetal bovine serum, $100 \mu \mathrm{g} / \mathrm{ml}$ streptomycin, and $100 \mathrm{IU} / \mathrm{ml}$ penicillin. HEK 293 cells were maintained in Dulbecco's modified Eagle's medium (DMEM) containing 10\% (v/v) fetal bovine serum, $100 \mu \mathrm{g} / \mathrm{ml}$ streptomycin, and $100 \mathrm{IU} / \mathrm{ml}$ penicillin. Stably transfected HEK 293 cells were maintained in $200 \mu \mathrm{g} / \mathrm{ml}$ G418, which was removed before the commencement of experiments. H295R cells were cultured in a 1:1 mixture of DMEM:F-12, containing $10 \mathrm{ml} / 1$ penicillin/streptomycin, 
$2.5 \% \mathrm{Nu}$-serum (BD Biosciences; Bedford, MA, USA) and 1X insulin/transferrin/selenium solution $(6 \cdot 25 \mu \mathrm{g} / \mathrm{ml}$ insulin, $6 \cdot 25 \mu \mathrm{g} / \mathrm{ml}$ transferrin, $6.25 \mu \mathrm{g} / \mathrm{ml}$ selenium, $1.25 \mathrm{mg} / \mathrm{ml}$ $\mathrm{BSA}$, and $5 \cdot 35 \mu \mathrm{g} / \mathrm{ml}$ linoleic acid; BD Biosciences). To create H295R cells stably expressing CD74 or the vector pcDNA4/ HisMax C, H295R cells were transfected with CD74 or vector pcDNA4/HisMax C using Lipofectamine 2000 (Invitrogen). Forty-eight hours after transfection, cells were split into fresh growth medium containing $100 \mu \mathrm{g} / \mathrm{ml}$ Zeocin (Invitrogen) with around $25 \%$ confluence. Selective medium was replenished every 3 days until Zeocin-resistant cells were detected. Expression of CD74 in this stable cell line was checked by western blot analysis using anti-Xpress antibody.

\section{Co-immunoprecipitation assay for AGTR 1 and CD74 interaction}

HEK 293 cells stably expressing the HA-AGTR 1 were plated onto polylysine-coated $100 \mathrm{~mm}$ diameter tissue culture dishes at a density of $10^{6}$ cells/dish and were transiently transfected with CD74 as described above, and used $48 \mathrm{~h}$ after transfection. The samples were cross-linked with the reversible cross-linker dithiobis(succinimidyl)propionate (DSP; Pierce, Rockford, IL, USA). DSP was added to a final concentration of $5 \mathrm{mM}$ and plates were incubated for $30 \mathrm{~min}$ at room temperature (Qian et al. 2001). The plates were placed on ice and washed twice with ice-cold PBS, and immunoprecipitation was performed with the $M$ MACS HA Isolation kit from Miltenyi Biotec (Bergisch Gladbach, Germany) according to the manufacturer's protocol. The eluted protein fraction was incubated at $37^{\circ} \mathrm{C}$ for $90 \mathrm{~min}$ and analyzed by western blotting.

\section{${ }^{125} \mathrm{I}-\left[\mathrm{Sar}^{1}, \mathrm{Ile}^{8}\right]$ AngII binding assay}

The number of AngII binding sites at the cell surface was determined by incubating the transiently transfected CHO-K1 cells or the stably transfected H295R cells with ${ }^{125}$ I- $\left[\mathrm{Sar}^{1}{ }^{1}\right.$ Ile $\left.^{8}\right]$ AngII (Hazleton Laboratories, Vienna, VA, USA) in the absence or presence of $1 \mu \mathrm{M}$ unlabeled $\left[\mathrm{Sar}^{1}, \mathrm{Ile}^{8}\right.$ ]AngII in E199 media for $6 \mathrm{~h}$ at $4{ }^{\circ} \mathrm{C}$. The cells were washed twice with ice-cold PBS, and lysed in $0.5 \mathrm{M}$ $\mathrm{NaOH}$, and $0.05 \%(\mathrm{w} / \mathrm{v})$ SDS solution. The cell-associated radioactivity was measured by $\gamma$-spectrometry, and AGTR 1 binding was calculated as the difference between the total count and that from samples incubated with the unlabeled antagonist. The data of experiments were analyzed by Student's $t$-test using Microsoft Excel. Values $P<0 \cdot 05$ were considered to be statistically significant.

\section{AGTR1 internalization in transiently transfected CHO-K1 cells}

To determine the internalization kinetics of the AGTR1,

${ }^{125}$ I-AngII $(2.5 \mathrm{kBq} / \mathrm{ml}(\sim 0.03 \mathrm{nM}))$ was added into $0.5 \mathrm{ml}$ E199 media and the cells were incubated at $37^{\circ} \mathrm{C}$ for the indicated times. Incubations were stopped by placing the plates on ice and washing twice with ice-cold PBS. Acid-released and acid-resistant radioactivities were separated and measured by $\gamma$-spectrometry as previously described (Hunyady et al. 1994). The percentage of internalized ligand at each time point was calculated from the ratio of the acid-resistant specific binding to the total (acid-resistant + acid-released) specific binding.

\section{Proteasomal and lysosomal inhibitor studies}

For inhibitor studies, CHO-K1 cells were transiently transfected with CD74 and the HA-AGTR1 or the empty pcDNA4/HisMax C vector and the HA-AGTR1 as described above. Forty-eight hours after transfection, cells were treated with the indicated inhibitors $(20 \mu \mathrm{M} \mathrm{MG}-132$, $1 \mathrm{mM}$ leupeptin, or $20 \mathrm{mM} \mathrm{NH} \mathrm{Nl}_{4} \mathrm{Cl}$ ) for $6 \mathrm{~h}$ before the binding assay was performed.

\section{Western blot analysis}

For immunodetection of expressed proteins, forty-eight hours after transfection, cells were scraped into $50 \mu \mathrm{L}$ Laemmli buffer containing protease inhibitor cocktail. After sonication and centrifugation, the supernatant proteins were analyzed on $8-16 \%$ or $12 \%$ Tris-glycine gels and transferred to polyvinylidene difluoride membranes. Blots were then probed with primary antibodies and detected with horseradish peroxidase-conjugated secondary antibodies using the SuperSignal West Pico or Dura detection kits (Pierce). For western blot analysis of phospho-p44/42 MAPK, the Odyssey infrared imaging system was used. H295R cells cultured in 6-well plates $\left(10^{6}\right.$ cells/well $)$ at $60 \%$ confluence were washed twice in serumfree medium and incubated overnight. After incubation, cells were washed with serum-free medium before treatment with AngII (100 nM) for the indicated times. Cells were then washed in ice-cold PBS and scraped into $100 \mu \mathrm{l} \mathrm{Laemmli} \mathrm{buffer.} \mathrm{After}$ sonication, centrifugation, and heating to $95^{\circ} \mathrm{C}$ for $5 \mathrm{~min}, 35 \mu \mathrm{l}$ of the extract sample was loaded onto $8-16 \%$ gel and western blot analysis was performed. Blots were blocked for $1 \mathrm{~h}$ in Odyssey blocking buffer (LI-COR Biosciences; Lincoln, NE, USA), and probed with phospho-p44/42 MAPK monoclonal antibody (Cell Signaling Technology; Danvers, MA, USA) and RPS6KA1 (Ribosomal S6 kinase 1) polyclonal antibody (Santa Cruz Biotechnology; Santa Cruz, CA, USA) overnight at $4{ }^{\circ} \mathrm{C}$. After washing four times for $5 \mathrm{~min}$ at room temperature in PBS containing $0 \cdot 1 \%$ Tween 20 with gentle shaking, blots were incubated with IRDye 680 Goat Anti-Rabbit IgG (LI-COR Biosciences) and IRDye $800 \mathrm{CW}$ Goat Anti-Mouse IgG (LICOR Biosciences) in 1: 20000 dilution for $1 \mathrm{~h}$ at room temperature. Immunofluorescence of phospho-MAPK and RPS6KA1 was analyzed in an Odyssey infrared imaging system (LI-COR Biosciences).

\section{Confocal laser-scanning microscopy}

CHO-K1 cells transiently transfected with the AGTR1-GFP or HEK 293 cells stably expressing the AGTR1-GFP were 
transiently transfected with either CD74 or deletion mutants of CD74 as described above, and were grown on glass coverslips. After $48 \mathrm{~h}$, the cells were washed twice with PBS prior to fixation with $4 \%(\mathrm{w} / \mathrm{v})$ paraformaldehyde. The cells were then incubated with sodium borohydride $(1 \mathrm{mg} / \mathrm{ml})$ for $15 \mathrm{~min}$ and permeabilized with $0 \cdot 1 \%(\mathrm{v} / \mathrm{v})$ Triton $\mathrm{X}-100$ in PBS. Incubation with anti-HA antibody (1:100) for $1 \mathrm{~h}$ at room temperature was followed by two 15-min washes with $25 \mathrm{mM}$ Tris- $\mathrm{HCl}(\mathrm{pH} 7 \cdot 4)$ containing $0 \cdot 14 \mathrm{M} \mathrm{NaCl}, 2 \cdot 7 \mathrm{mM} \mathrm{KCl}$, $0 \cdot 1 \%(\mathrm{v} / \mathrm{v})$ Tween 20 , and incubation for $1 \mathrm{~h}$ with Alexa 594conjugated goat anti-mouse antibody (1:1000). The coverslips were mounted using Aquapolymount (Polysciences, Inc., Warrington, PA, USA) fluorescence mounting medium, and images were detected with a Zeiss LSM 510 confocal laserscanning microscope. GFP or FITC and Alexa 594 were excited with argon $(488 \mathrm{~nm})$ and helium/neon $(543 \mathrm{~nm})$ lasers, and emitted fluorescence was detected in multi-track mode with 500-550 and 565-615 nm bandpass filters respectively. Image analysis was performed by using LSM Image Examiner. The value for fluorescence intensity ratio of AGTR1-GFP localized at the plasma membrane and in the cytosol was calculated by averaging the fluorescence intensity of pixels of defined plasma membrane and cytosolic areas (excluding the nucleus) and subtracting the non-specific background from outside the cell.

\section{Results}

Identification of CD74 as an interacting protein for the AGTR1 carboxyl-terminal tail in yeast two-hybrid assay

To identify novel proteins interacting with the human AGTR1, a human kidney cDNA library was screened using the AGTR1 carboxyl-terminal tail (amino acids 301-359) as a bait that was modified by replacing residues T332, S335, T336 to aspartic acid to mimic the phosphorylation state of the receptor. Screening of $9 \times 10^{7}$ transformants resulted in 13 independent clones that were putatively positive. One of the cDNAs isolated was $1200 \mathrm{bp}$ long and encoded an open reading frame for 206 amino acids. Blast homology searches revealed 99\% DNA sequence identity with the human invariant chain of the MHC, class II antigen associated (CD74).

\section{Association of the AGTR1 and CD74 in transfected cells}

In order to determine whether the AGTR1 interacts with CD74 in mammalian cells, HEK 293 cells stably expressing the HA-AGTR1 were transiently transfected with CD74. The cells were harvested, and the HA-AGTR1 was precipitated with $\mu$ MACS anti-HA MicroBeads. The precipitates were analyzed by SDS-PAGE and CD74 was detected using antibody against its Xpress tag. As shown in Fig. 1A, co-immunoprecipitation of CD74 with the HA-AGTR1 was observed when the HA-AGTR1 was permanently expressed in the HEK 293 cells. Figure 1B shows the expression of HA-AGTR1 and CD74 in the cell lysates

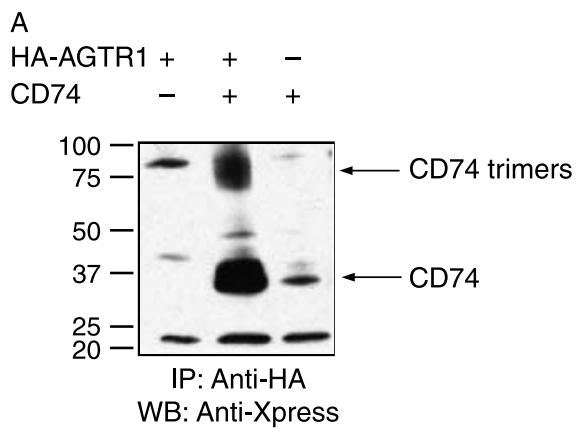

B
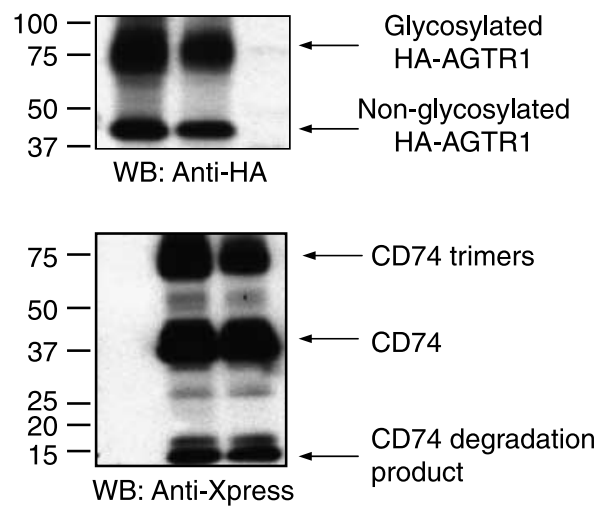

Figure 1 CD74 interacts with the AGTR1. (A) HEK 293 cells stably transfected with the HA-AGTR1 were transiently co-transfected with Xpress-tagged CD74. Immunoprecipitation was performed with $\mu$ MACS anti-HA MicroBeads followed by western blot analysis with the Xpress-tag antibody to visualize CD74 co-immunoprecipitation with the HA-AGTR1. (B) Western blotting of the input lysate against HA-AGTR1 with anti-HA antibody (upper panel) and Xpress-tagged CD74 with anti-Xpress antibody (lower panel). Arrows indicate the non-glycosylated and glycosylated forms of the HA-AGTR1 and the monomer and trimer forms of CD74 and its lysosomal degradation product. The data are representative of three similar experiments.

and arrows indicate the non-glycosylated and glycosylated forms of the HA-AGTR 1 and the monomer and trimer forms of CD74 and its lysosomal degradation product.

The intracellular localization of transiently expressed CD74 in HEK 293 cells stably expressing the AGTR1-GFP was analyzed by immunostaining. The AGTR1-GFP protein used for confocal microscopy studies has been previously shown to have similar signaling, trafficking, and phosphorylation characteristics in HEK 293 cells as the non-tagged or HA-tagged AGTR1, despite the relatively large GFP tag on its carboxyl terminus (Hunyady et al. 2002). Immunostaining of the Xpress epitope tag ofCD74 revealed co-localization with the AGTR1GFP in a region adjacent to the nucleus, consistent with that of the ER (Fig. 2A). Co-localization in the ER region was also observed in CHO-K1 cells transiently co-transfected with the AGTR1-GFP and CD74 (Fig. 2B, upper panels). In these cells, the localization of CD74 was confirmed by its co-localization with the ER marker protein, calreticulin (Fig. 2C).

www.endocrinology-journals.org 
A AGTR1-GFP

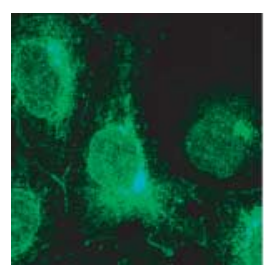

B AGTR1-GFP

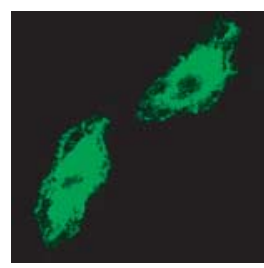

C Calreticulin

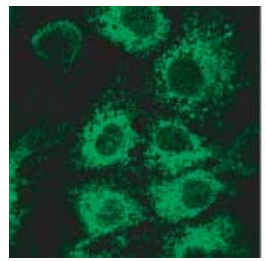

CD74

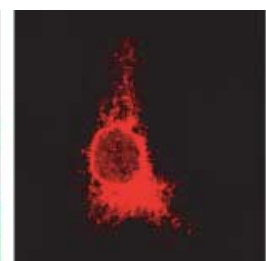

CD74

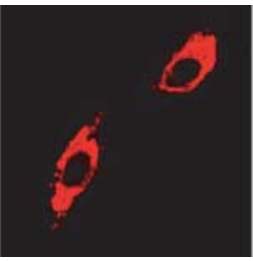

CD74

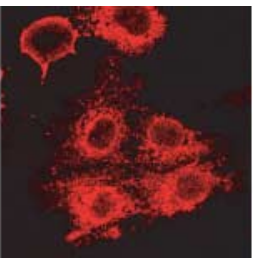

Merge

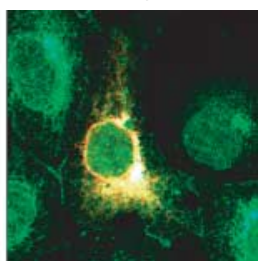

Merge

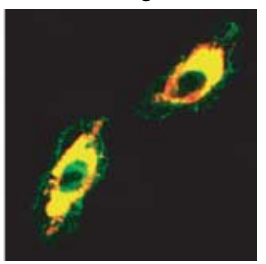

Merge

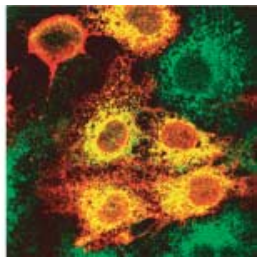

Figure 2 Co-localization of AGTR1-GFPand CD74 in the ER. (A) HEK 293 cells stably transfected with the AGTR1-GFP were transiently co-transfected with Xpress-tagged CD74. The cells were fixed and stained with anti-Xpress antibody and Alexa 594-conjugated secondary antibody to visualize CD74. The fluorescence of AGTR1GFP is shown in green (left panel) and localization of Xpress-tagged $\mathrm{CD} 74$ is shown in red (middle panel). (B) CHO-K1 cells were transiently co-transfected with the AGTR1-GFP (left panel) and Xpresstagged CD74. The cells were fixed and stained with anti-Xpress antibody to visualize CD74 (middle panel). (C) CHO-K1 cells were transiently transfected with Xpress-tagged CD74. The cells were fixed and stained with anti-Xpress antibody (middle panel) and calreticulin antibody as an ER marker (left panel). Typical cells are shown from a representative example of three experiments with identical results.

\section{Down-regulation of AGTR1 cell surface expression by CD74}

To investigate the possible functional role of a direct interaction between CD74 and the AGTR1, cell surface expression of the HA-AGTR1 was determined. Analysis of the ${ }^{125} \mathrm{I}-\left[\mathrm{Sar}^{1}\right.$,I$\left.1 e^{8}\right]$ AngII binding to $\mathrm{CHO}-\mathrm{K} 1$ cells transiently co-expressing the HA-AGTR 1 and CD74 revealed a significant reduction in cell surface expression of the HA-AGTR 1 (Fig. 3A). To confirm that the changes in the ${ }^{125} \mathrm{I}-\left[\mathrm{Sar}^{1}, \mathrm{Ile}^{8}\right]$ AngII binding are due to the decreased expression of the AGTR1 at the cell surface, western blot analysis was performed on lysates of $\mathrm{CHO}-\mathrm{K} 1$ cells transiently co-expressing the HA-AGTR1 and CD74. Overexpression of CD74 with the HA-AGTR 1 caused a significant reduction of the HA-AGTR1 protein level corresponding to the glycosylated form of the HA-AGTR1 (Fig. 3B). These results suggest that $\mathrm{CD} 74$ interferes with the surface expression of AGTR1. However, no change in the CD74 protein expression level was observed when the AGTR1 was co-expressed (data not shown).
A
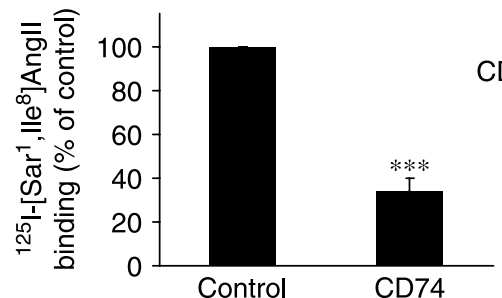

B

Figure 3 Cell surface expression of AGTR1 in CHO-K1 cells transiently co-transfected with $\mathrm{CD} 74$. (A) $\mathrm{CHO}-\mathrm{K} 1$ cells were grown in 24-well plates and co-transfected with $0.5 \mu \mathrm{g}$ HA-AGTR1 cDNA and $0.5 \mu \mathrm{g}$ empty pcDNA4/HisMax C vector (control) or $0.5 \mu \mathrm{g}$ HA-AGTR1 cDNA and 0.5 $\mu \mathrm{g}$ CD74). Cell surface expression levels of the AGTR1 were measured by ${ }^{125} \mathrm{I}-\left[\mathrm{Sar}^{1}, \mathrm{Ile}^{8}\right]$ Angll binding. Data are shown as means \pm s.E.M. of seven independent experiments, each performed in duplicate. ${ }^{* * *} P<0 \cdot 001$ versus control. (B) Representative immunoblot showing expression levels of HA-AGTR1 in cells co-transfected with the empty pcDNA4/HisMax C vector or CD74. Anti-HA antibody was used to detect the HA-AGTR1 level by western blot analysis. Lower arrow indicates the non-glycosylated and upper arrow indicates the glycosylated forms of the HA-AGTR1. The data are representative of three such experiments performed.

\section{Inducible AGTR 1 expression in CHO-K1 Tet-On cells}

To determine whether the reduction of the surface expression of AGTR 1 caused by CD74 expression occurs on the biosynthetic pathway or after the export of AGTR 1 to the plasma membrane and its internalization to endosomal compartments, the Tet-On system was used for inducible, regulated AGTR 1 expression. CHO-K1 Tet-On cells transiently transfected with the tetracycline-responsive plasmid containing the HA-AGTR1 were co-transfected with either CD74 or the empty vector cDNA. The cells were exposed to $1 \mu \mathrm{g} / \mu \mathrm{l}$ concentration of doxycycline for increasing time intervals, to control transcription of the HA-AGTR1. The cell surface receptor expression was determined by ${ }^{125} \mathrm{I}-\left[\mathrm{Sar}^{1}{ } \mathrm{Ile}^{8}\right]$ AngII binding at each time point. The cell-bound radioactivity is shown in Fig. 4 as percentage of binding after $24 \mathrm{~h}$ of doxycycline induction. In the Tet-On system, the doxycycline-controlled expression of the HA-AGTR 1 was markedly inhibited beginning from the earliest stage of receptor expression, when CD74 was co-expressed with the HA-AGTR1. No HA-AGTR1 was detected at the cell surface during the first $6 \mathrm{~h}$ of CD74 co-expression, indicating that down-regulation of the AGTR1 occurs in the biosynthetic pathway and not after its expression at the plasma membrane.

\section{CD74 does not influence internalization of the AGTR1 from} the plasma membrane

Although our microscopy studies did not show the presence of CD74 at the plasma membrane, $2-5 \%$ of CD74 was expressed at the cell surface in other reports (Sant et al. 1985, Wraight et al. 1990). This raised the possibility that an interaction between the AGTR1 and CD74 may occur at the plasma membrane, and that CD74 may increase the internalization of the AGTR1 and its trafficking to lysosomal compartments for degradation. 


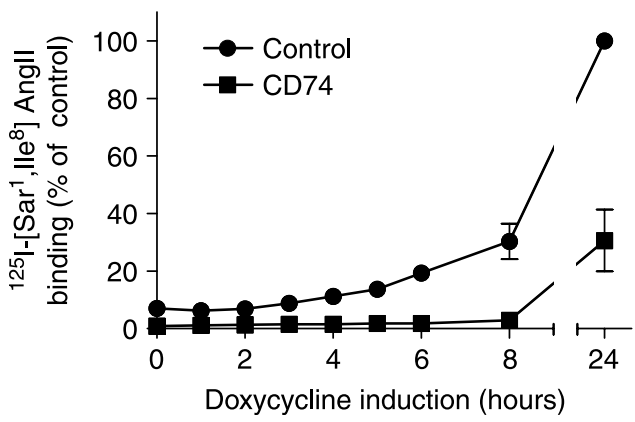

Figure 4 Effect of overexpressed CD74 on doxycycline-induced expression of AGTR1 in CHO-K1 Tet-On cells. CHO-K1 Tet-On cells were grown in 24-well plates and co-transfected with $0.5 \mu \mathrm{g}$ AGTR1 cDNA containing pTRE-Tight plasmid and $0.5 \mu \mathrm{g}$ empty pcDNA4/HisMax C ( control) or $0.5 \mu \mathrm{g}$ AGTR1 cDNA containing pTRE-Tight plasmid and $0.5 \mu \mathrm{g}$ CD74 ( $\mathrm{CD} 74)$. Forty-eight hours after transfection, cells were incubated with $1 \mu \mathrm{g} / \mathrm{ml}$ doxycycline for the indicated times. Cell surface expression levels of the AGTR1 were measured by ${ }^{125} \mathrm{I}-\left[\mathrm{Sar}^{1}, \mathrm{Ile}^{8}\right]$ Angll binding. Data are shown as means \pm s.E.M. of three independent experiments, each performed in duplicate.

To further investigate the possibility that CD74 interacts with the AGTR1 at the plasma membrane, receptor internalization studies were performed. Transient co-expression of CD74 with the HA-AGTR1 had no effect on receptor internalization (Fig. 5), consistent with our results with the tetracyclineregulated AGTR1 expression system and our observation by immunostaining that the AGTR1 and CD74 are associated in the biosynthetic pathway.

\section{CD74 binding site in the membrane-proximal region of} the AGTR 1

The CD74 binding region within the AGTR1 carboxylterminal tail was determined by studies on AGTR1 mutants.

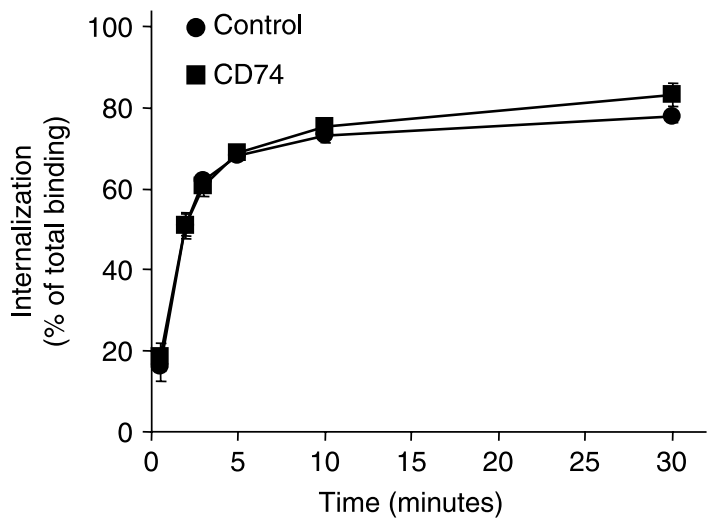

Figure 5 Effect of overexpressed CD74 on the kinetics of AGTR1 internalization in $\mathrm{CHO}-\mathrm{K} 1$ cells. $\mathrm{CHO}-\mathrm{K} 1$ cells were grown in 24-well plates and co-transfected with $0.5 \mu \mathrm{g}$ AGTR1 cDNA-containing plasmid and $0.5 \mu \mathrm{g}$ empty pcDNA4/HisMax C ( control) or $0.5 \mu \mathrm{g}$ CD74 ( $\mathbf{a}$ CD74). Internalization of ${ }^{25}$ I-Angll was measured. Data are shown as means \pm s.E.M. of three independent experiments, each performed in duplicate.
The membrane-proximal region of the cytoplasmic tail is required for normal AGTR1 folding and surface expression. In COS-7 cells, removal of amino acids beyond residue 309 causes complete loss of receptor expression. Expression of the AGTR1 lacking the receptor tail from residue 319 (AGTR1 $1 \Delta 319$ ) was $50 \%$ lower than that of the wild-type receptor (Gaborik et al. 1998). Its co-expression with CD74 also lowered the expression level of AGTR1D319 (Fig. 6), indicating that CD74 binds to the receptor tail upstream from the 318 amino acid.

\section{The N-terminal region of CD74 is necessary for AGTR1 binding}

We sought to identify the AGTR1 binding site on CD74 by using a series of deletion constructs of CD74, and testing for changes in ${ }^{125} \mathrm{I}-\left[\mathrm{Sar}^{1}, \mathrm{Ile}^{8}\right]$ AngII binding in cells co-expressing AGTR1 with the different truncated CD74 mutants. CD74 has a short cytoplasmic N-terminal tail containing two dileucine-based endosomal targeting motifs that mediate its interaction with the clathrin adaptor AP1 and AP2 proteins (Kongsvik et al. 2002), and its internalization from the plasma membrane to the trans-Golgi network (Hofmann et al. 1999). It also contains an arginine-based ER retention signal that maintains type II membrane proteins in the ER, and is followed by a single transmembrane domain and a long carboxyl-terminal extracytoplasmic region (Michelsen et al. 2005). This region of CD74 is required for class II assembly, whereas the 80-104 region (CLIP) mediates association with class II molecules, giving rise to nanomers, and the 153-183 region is involved in the formation of CD74 trimers (Bertolino \& Rabourdin-Combe 1996). The schematic of the deletion mutants of CD74 used in the binding experiments is shown in Fig. 7A. The binding of ${ }^{125} \mathrm{I}-\left[\mathrm{Sar}^{1}, \mathrm{Ile} \mathrm{e}^{8}\right]$ AngII to the cells transfected with the constructs with the deletion of residues $123(\Delta 123-C D 74)$ and $72(\Delta 72-C D 74)$, which remove the CLIP domain and transmembrane domain respectively, was

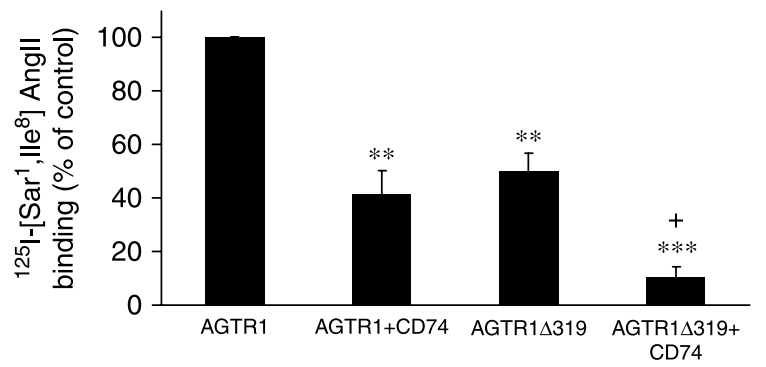

Figure 6 Effect of overexpressed CD74 on the surface expression of carboxyl-terminal AGTR1 deletion mutants. Cell surface expression levels of wild-type (AGTR1) and deletion mutant AGTR1 (AGTR1 $\Delta 319$ ) co-expressed with empty pcDNA4/HisMax C vector or CD74 were measured by ${ }^{125} \mathrm{I}-\left[\mathrm{Sar}^{1}, \mathrm{Ile}^{8}\right]$ Angll binding in $\mathrm{CHO}-\mathrm{K} 1$ cells. ${ }^{125}$ I- $\left[\mathrm{Sar}^{1}, \mathrm{Ile}^{8}\right]$ Angll binding of AGTR1 was considered as control. Data are shown as means \pm S.E.M. of three independent experiments, each performed in duplicate. ${ }^{* *} P<0 \cdot 01$ and ${ }^{* * *} P<0 \cdot 001$ versus AGTR1. ${ }^{+} P<0 \cdot 01$ versus AGTR1 319 . 
A

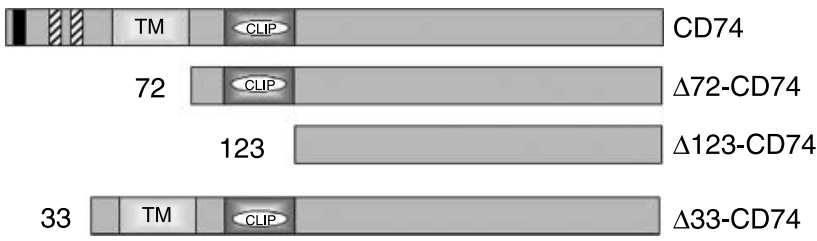

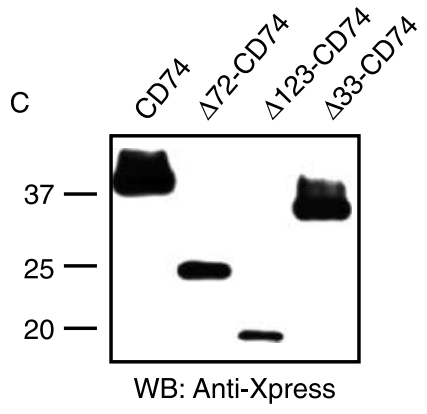

B

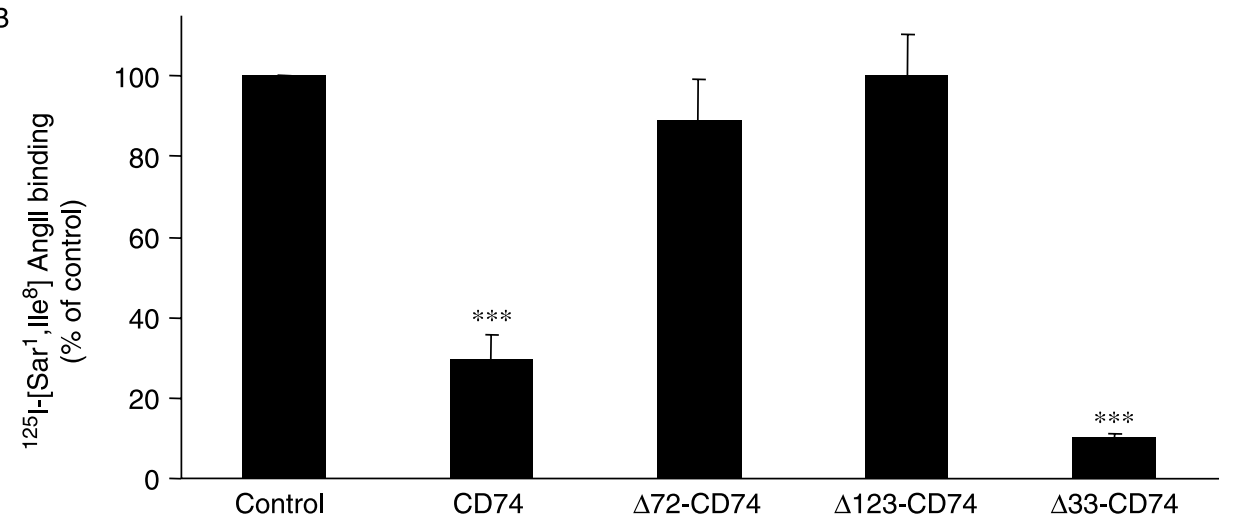

Figure 7 Mutant CD74 constructs and the effect of their overexpression on AGTR1 cell surface expression. (A) Schematic of CD74 mutants used in the present study. $\Delta 33-C D 74, \Delta 72-C D 74$, and $\Delta 123-C D 74$ are $\mathrm{N}$-terminal deletion mutants of CD74 from position, 33, 72, and 123 respectively. (B) Surface expression of HA-AGTR1 was measured by ${ }^{125} \mathrm{I}-\left[\mathrm{Sar}^{1}, \mathrm{Ile}^{8}\right]$ Angll binding in $\mathrm{CHO}-\mathrm{K} 1$ cells transiently co-transfected with the HA-AGTR1 and the wild-type or mutant CD74 constructs. For control, 0.5 $\mu \mathrm{g}$ HA-AGTR1 cDNAcontaining plasmid and $0.5 \mu \mathrm{g}$ empty pcDNA4/HisMax $\mathrm{C}$ were co-transfected. Data are shown as means \pm s.E.M. of three independent experiments, each performed in duplicate. ${ }^{* * *} P<0 \cdot 001$ versus control. (C) Expression levels of wild-type and mutant CD74 constructs were detected by western blot analysis with Xpress antibody. The data are representative of three such experiments performed.

unchanged (Fig. 7B). This indicates that these mutations abolish the interaction with the HA-AGTR1, suggesting that the region downstream of residue 72 is necessary for HA-AGTR 1 association. Deletion of the N-terminal region, and removal of the two dileucine-based endosomal targeting signal, increases the level of CD74 at the plasma membrane (Nakatsu et al. 2000). Co-expressing the CD74 deletion mutant lacking the first 33 residues of the amino-terminal part decreased HA-AGTR 1 binding (Fig. 7B). This indicates that this mutant still interacts with the HA-AGTR 1 and that the HA-AGTR 1 binding site on CD74 is located on its aminoterminal region between residues 34 and 71 . The expression levels of CD74 mutants were determined by western blot analysis (Fig. 7C).

Co-localization studies by immunostaining of the Xpress epitope tag of the mutant CD74 proteins co-expressed with the AGTR1-GFP confirmed our conclusions from the binding studies (Fig. 8A). The $\Delta 72-C D 74$ and $\Delta 123-C D 74$ deletion mutants showed diffuse cytoplasmic localization and no co-localization with the AGTR1-GFP. However, the proximal amino-terminal deletion mutant CD74
$(\Delta 33-C D 74)$, which showed increased plasma membrane localization, still co-localized with the AGTR1-GFP in the ER region and aggregates were seen in the ER. For the semiquantitative analysis of the AGTR1-GFP number at the plasma membrane in these cells, the fluorescence intensity ratio of AGTR1-GFP localized at the plasma membrane and in the cytosol was calculated (Fig. 8B). The fluorescence intensity of the AGTR1-GFP at the plasma membrane is significantly decreased in the cells co-expressing CD74 or $\Delta 33-$ CD74 with the AGTR1-GFP which is in agreement with the binding data.

AGTR1s in the presence of CD74 are targeted to the proteasomal degradation pathway

To analyze the possible degradation pathways of the AGTR 1 in cells expressing CD74, inhibitors of proteasomal and lysosomal degradation were used. Proteasomal activity was suppressed by addition of MG-132, a specific proteasome inhibitor. To analyze lysosomal contribution, we used both leupeptin, an inhibitor of cysteine proteases, and $\mathrm{NH}_{4} \mathrm{Cl}$, a weak base that increases 

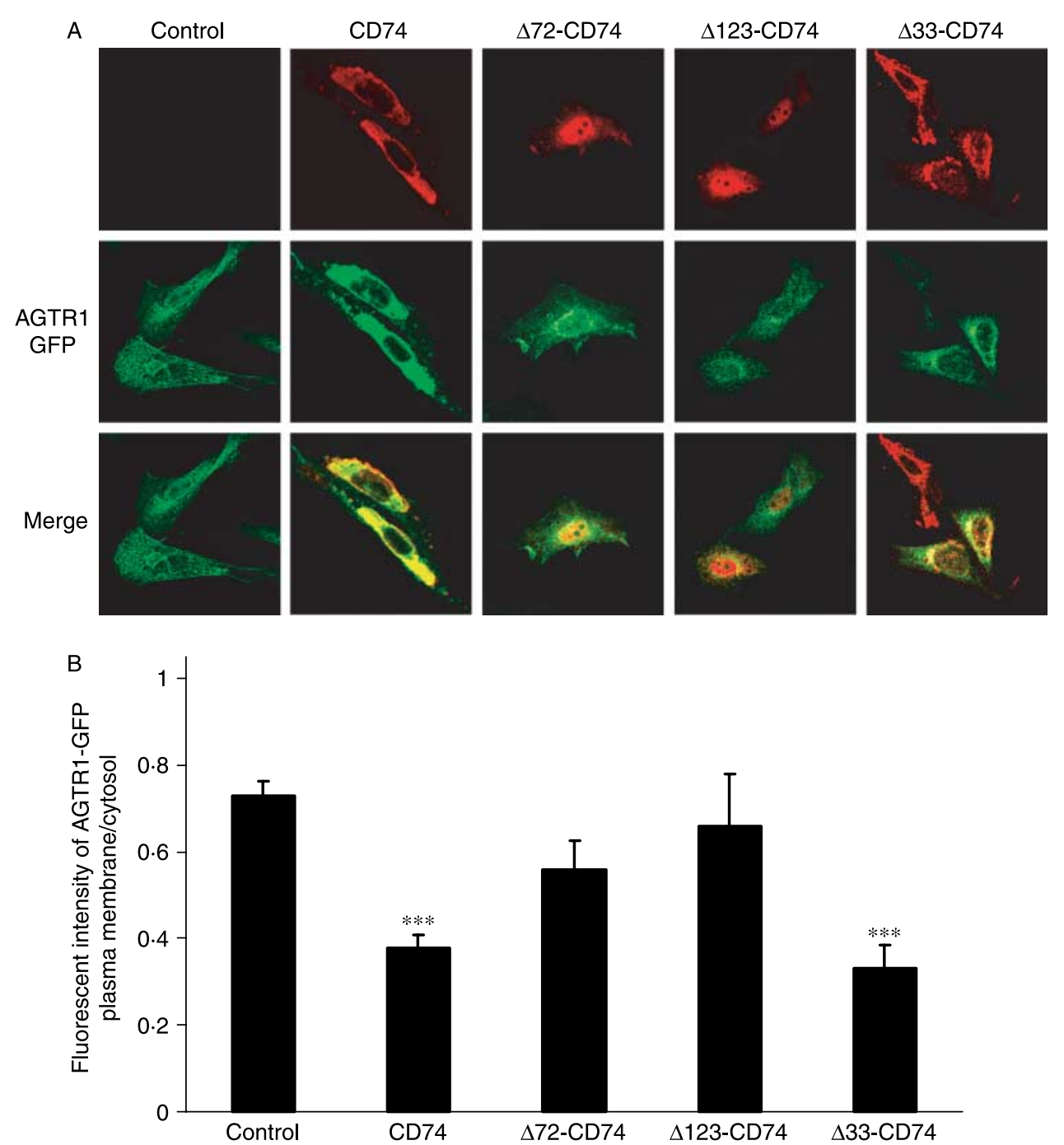

Figure 8 Subcellular localization of co-transfected CD74 mutants and AGTR1-GFP. (A) CHO-K1 cells were transiently co-transfected with the AGTR1-GFP and Xpress-tagged CD74 mutants. The cells were fixed and stained with anti-Xpress antibody. The fluorescence of AGTR1GFP is shown in green (middle panels) and localization of Xpress-tagged CD74 mutants are shown in red (upper panels). Typical cells are shown from a representative example of three experiments with identical results. (B) Fluorescence intensity ratio of AGTR1-GFP localized at the plasma membrane and in the cytosol was calculated by averaging the fluorescence intensity of pixels of defined plasma membrane and cytosolic areas (excluding nucleus) and subtracting the non-specific background from outside the cell. Each value is means \pm s.E.M. of at least four determinations in each experiment. ${ }^{* * *} P<0 \cdot 001$ versus control.

lysosomal $\mathrm{pH}$ and thereby inhibits the proteolytic activity of lysosomal enzymes. Leupeptin inhibits the trafficking of $\mathrm{MHC}$ class II molecules and degradation of CD74 in the lysosome, causing accumulation of the MHC class II-CD74 complex therein and reduction of its cell surface expression (Loss \& Sant 1993). Transiently transfected CHO-K1 cells were incubated in the absence or presence of inhibitors for $6 \mathrm{~h}$, and HA-AGTR 1 expression was determined by ${ }^{125} \mathrm{I}-\left[\mathrm{Sar}^{1}, \mathrm{Ile}^{8}\right]$ AngII binding assay. Inhibition of proteasomal activity by MG-132 enhanced HA-AGTR 1 accumulation at the cell surface when CD74 was co-expressed, compared with the expression of the receptor only. By contrast, the lysosomal inhibitor had no significant effect on the cell surface level of the HA-AGTR1 (Fig. 9). Collectively, these data suggest that degradation by the proteasome system limits AGTR1 expression when CD74 is co-expressed.

\section{Down-regulation of endogenous AGTR1 signaling by CD74}

The human adrenocortical cell line H295R expresses endogenous AGTR 1 and secretes aldosterone in response to AngII. In these cells AngII activates p44/42 MAPK with a peak of 5 min lasting up to hours (Natarajan et al. 2002). To prove that CD74 is capable of interfering with the plasma membrane expression of 


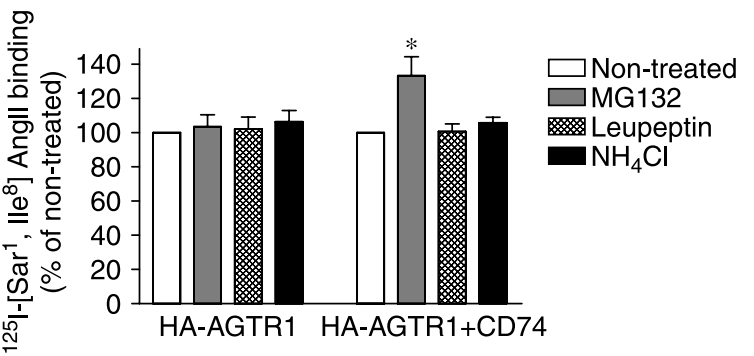

Figure 9 Effects of inhibitors of the proteasomal and lysosomal pathways on the surface expression of the AGTR1. CHO-K1 cells were grown in 24-well plates and co-transfected with $0.5 \mu \mathrm{g}$ HA-AGTR1 and $0.5 \mu \mathrm{g}$ empty pcDNA4/HisMax C vector or $0.5 \mu \mathrm{g}$ HA-AGTR1 and $0.5 \mu \mathrm{g}$ CD74. Forty-eight hours after transfection, the cells were incubated with $20 \mu \mathrm{M} \mathrm{MG}-132,1 \mathrm{mM}$ leupeptin, or $20 \mathrm{mM} \mathrm{NH}_{4} \mathrm{Cl}$, or were untreated for $6 \mathrm{~h}$. Cell surface expression levels of the HA-AGTR1 were measured by ${ }^{125} \mathrm{I}-\left[\mathrm{Sar}^{1},{ }^{1} \mathrm{Ie}^{8}\right]$ AngIl binding and are shown as percentage of ${ }^{125} \mathrm{I}-\left[\mathrm{Sar}^{1}, \mathrm{Il} \mathrm{e}^{8}\right]$ Angll binding of HA-AGTR1 in non-treated samples. Data are means \pm S.E.M. of three independent experiments, each performed in duplicate. ${ }^{*} P<0 \cdot 05$ versus control.

the endogenous AGTR1, H295 cells stably expressing CD74 were used for ${ }^{125} \mathrm{I}-\left[\mathrm{Sar}^{1}, \mathrm{Ile}^{8}\right]$ AngII binding and signaling pathway analysis. Stable overexpression of CD74 in H295R cells significantly decreased ${ }^{125} \mathrm{I}-\left[\mathrm{Sar}^{1}, \mathrm{Ile}^{8}\right]$ AngII binding compared with the cells overexpressing the empty pcDNA4/ HisMax C vector (Fig. 10A). We next investigated the effect of CD74 overexpression on the downstream signaling events of the

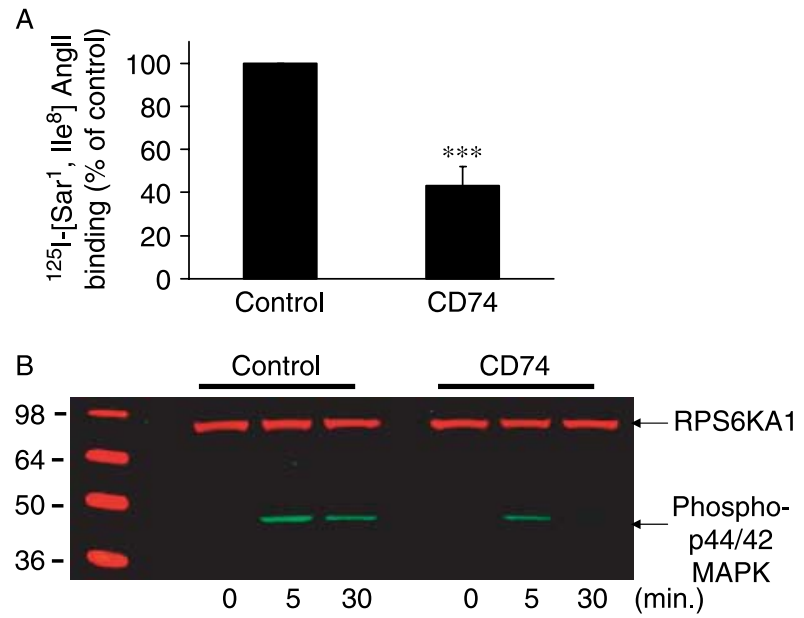

Figure 10 Effect of overexpressed CD74 on the surface expression of the endogenous AGTR1 in H295R cells. (A) H295R cells were stably transfected with the empty pcDNA4/HisMax C vector (control) or CD74. Cell surface expression levels of the endogenous AGTR1 were measured by ${ }^{125} \mathrm{I}-\left[\mathrm{Sar}^{1}, \mathrm{Ile}^{8}\right]$ Angll binding. Data are shown as means \pm S.E.M. of seven independent experiments, each performed in duplicate. ${ }^{* * *} P<0 \cdot 001$ versus control. (B) Representative immunoblot showing expression levels of RPS6KA1 and phospho-p44/42 MAPK in H295R cells stably transfected with the empty pcDNA4/HisMax C vector (control) or CD74. Cells were stimulated with $100 \mathrm{nM}$ Angll for the indicated times. The data are representative of three such experiments. endogenous AGTR1 stimulation. Phosphorylation of the p44/ 42 MAPK was detected by western blotting with specific antibodies at several time points after stimulation of $\mathrm{H} 295 \mathrm{R}$ cells with 100 nM AngII (Fig. 10B). The phospho-p44/42 MAPK signal was decreased when CD74 was stably expressed in H295R cells due to the reduced amount of AGTR1 on the cell surface. The signal of RPS6KA1 used as a control for equal protein loading was unaffected.

\section{Discussion}

The AngII-activated AGTR1 is phosphorylated by specific G protein-coupled receptor kinases (GRKs) at the plasma membrane (Oppermann et al. 1996, Thomas 1999, Hunyady et al. 2000, Olivares-Reyes et al. 2001). To mimic the phosphorylation state of the AGTR1, we replaced residues T332, S335, and T336 with aspartic acid and used this modified AGTR1 carboxyl-terminal tail in yeast two-hybrid studies to identify AGTR1-associated proteins. This revealed that the MHC class II chaperone, CD74, undergoes association with the carboxyl-terminal region of the AGTR1. However, our studies of co-localization, binding assay, and co-immunoprecipitation with the non-phosphorylated native AGTR1 indicate that the non-phosphorylated AGTR1 interacts with CD74. This is consistent with the location of the binding site for CD74 above these phosphorylation sites. These findings have demonstrated that interaction of CD74 with the AGTR1 occurs in the biosynthetic pathway before the receptor reaches the plasma membrane and prior to its phosphorylation. However, our studies do not exclude the possibility that the phosphorylation state of the AGTR1 may influence its interaction with CD74.

Although relatively little is known about the transport of $\mathrm{G}$ protein coupled receptors (GPCRs) to the cell surface, a crucial role for the membrane-proximal region of the carboxyl-terminal tail has been shown for several GPCRs. This corresponds to the putative helix 8 , which is an $\boldsymbol{\alpha}$-helix with amphipathic properties. Several GPCRs lacking the carboxyl terminus are not expressed at the cell surface, suggesting the presence of an export motif in this domain and roles of chaperone proteins that bind to this region and regulate receptor trafficking in the biosynthetic pathway (Gaborik et al. 1998). The sequence $\mathrm{F}(\mathrm{X})_{6} \mathrm{LL}$ is highly conserved in the membrane-proximal carboxyl terminus of many GPCRs and functions as a common motif mediating receptor transport from the ER to the cell surface (Duvernay et al. 2004, Thielen et al. 2005). It is also necessary for receptor folding in the ER and to pass the quality control system. It is interesting that the site of CD74 binding to the AGTR1 is located in this region, which contains the $\mathrm{F}(\mathrm{X})_{6} \mathrm{LL}$ motif that has been previously found to be important in AGTR1 exit from the ER and folding (Gaborik et al. 1998), and is recognized as a caveolin-like binding motif (Leclerc et al. 2002). In the case of the dopamine D1-receptor, the membraneassociated ER protein, DRIP78 (also known as DNAJC14) was found to interact with this membrane-proximal region of the 
receptor. Overexpression of DRIP78 led to retention of the D1 receptor in the ER (Bermak et al. 2001). Overexpression of DRIP78 with the AGTR1 increased the plasma membrane expression of the receptor (Leclerc et al. 2002). In several GPCRs, homo- or hetero-dimerization is a prerequisite for their exit from the ER and their membrane expression. For example, the formation of heterodimers between GABBR1 (also known as GABRB1) and GABBR2 (also known as GABRB2) is required for functional expression. Also, 14-3-3 proteins were found to be associated with the GABBR 1 carboxyl terminus, and to impede the interaction between the two receptor carboxyl termini (Couve et al. 2001). Olfactory GPCRs are inefficiently expressed at the plasma membrane of heterologous cells due, in part, to degradation of the ER-retained receptors by the ubiquitin-proteasome system (Lu et al. 2003). These findings suggest the necessity of endogenous chaperones for the expression of GPCRs at the plasma membrane.

Our data indicate that the AGTR 1 co-expressed with CD74, like the carboxyl-terminal-deficient mutants and misfolded receptors, aggregates in the ER and undergoes degradation by the proteasomal system. The role of the proteasomal system in AGTR 1 degradation during CD74 co-expression was demonstrated by the effect of its inhibition with MG-132. That co-immunoprecipitation could be performed only in stably transfected cells confirms the finding that CD74 directs the proteasomal degradation of the receptor. In transiently co-transfected cells, the receptor cannot reach a sufficiently high level of expression for successful co-immunoprecipitation when co-expressed with CD74.

The targeting of MHC class II molecules to the endocytic compartments, where they encounter processed antigen, and their exit from the ER, are determined by CD74. This trafficking pathway is mediated by the cytoplasmic tail of CD74, which contains two dileucine-based targeting motifs that are required for its lysosomal targeting and endocytosis from the plasma membrane (Kang et al. 1998). It also contains an arginine-based ER retention motif at the proximal N-terminus, which is conserved in type II membrane proteins (Michelsen et al. 2005). Phosphorylation of two serine residues in the neighborhood of the arginine-based signals regulates the exit of the MHC class II-CD74 complex from the ER (Anderson \& Roche 1998, Kuwana et al. 1998). CD74 associates with 14-3-3 proteins in a phosphorylation-dependent manner, and this interaction results in shielding of the arginine-based signal. When the $\mathrm{N}$-terminus is not phosphorylated, $\beta \mathrm{COP}$ binds even in the presence of the 14-3-3 $\beta$ protein. Upon phosphorylation, $14-3-3 \beta$ binds and $\beta \mathrm{COP}$ association is suppressed, stimulating forward trafficking of the MHC class II-CD74 complex (O'Kelly et al. 2002). Inhibition of CD74 phosphorylation impairs the trafficking of newly synthesized MHC class II molecules to antigen-processing compartments. Protein kinase $\mathrm{C}$ is responsible for the constitutive phosphorylation of $50 \%$ of the total cellular pool of CD74. Stimulation of protein kinase C activity in antigen-presenting cells significantly enhances the kinetics of degradation of class II-associated CD74 in the antigen-processing compartments, and the binding of antigenic peptides to the class II molecules. In cells expressing a CD74-phosphorylation mutant, trafficking of class II molecules to endosomes is impaired and CD74 proteolysis is inhibited, consistent with a direct effect of CD74 phosphorylation on MHC class II trafficking (Anderson et al. 1999).

In our study, N-terminal truncation and removal of the two dileucine- and arginine-based targeting signals of CD74 $(\Delta 33-\mathrm{CD} 74)$ reduced the surface expression of the AGTR1, indicating its binding to the receptor. Interestingly, although N-terminal-deleted CD74 still binds the AGTR1 in the ER, it has increased plasma membrane localization according to our confocal microscopy studies and as reported previously (Nakatsu et al. 2000).

The fraction of CD74 that is not associated with MHC class II molecules is transported to the plasma membrane and rapidly internalized with a half-life of 3-4 min (Roche et al. 1993). About $2-5 \%$ of the total CD74 is expressed at the plasma membrane, where it acts as a receptor for MIF and is required for its activation of MAPK (Leng et al. 2003). MHC class II molecules appear to reach the lysosomal compartment together with CD74 via the plasma membrane (McCormick et al. 2005). Nonetheless, our confocal microscopy experiments did not reveal CD74 expression and its co-localization with the AGTR1-GFP at the plasma membrane. In addition, CD74 is a member of the regulated intramembrane proteolysis-processed protein family. After intramembranous cleavage in the endocytic compartments, the cytosolic CD74 fragment is released and induces the activation of transcription mediated by the NFXBp65/RELA homodimer and the B-cell-enriched co-activator, TAF(2)105, by translocation to the nucleus (Becker-Herman et al. 2005).

In summary, we have identified CD74 as an interacting protein with the carboxyl-terminal domain of the AGTR1 in the biosynthetic pathway. Based on our results, CD74 appears to function as a negative regulator of AGTR 1 expression at the cell surface. Because of the wide expression of CD74, dominant negative approaches could be helpful to elucidate the function of the endogenous CD74 protein in the expression of the AGTR1. Since CD74 can be expressed separately from MHC class II molecules in various tissues, and its expression is increased in inflammatory processes (Momburg et al. 1986), changes in CD74 expression may have a significant role in the regulation of AGTR 1 expression at the cell surface under specific conditions. This could result from its ability to direct certain of the newly synthesized AGTR1 molecules from the ER to their degradation in the proteasome.

\section{Declaration of interest}

The authors have nothing to declare.

\section{Funding}

This work was supported by the NIH Intramural Research Program, Eunice Kennedy Shriver National Institute of Child Health and Human Development. 


\section{Acknowledgements}

We thank Tamas Balla and Balazs Mihalik for their valuable discussions. Microscopy imaging was performed at the Microscopy \& Imaging Core (National Institute of Child health and Development, NIH). We are grateful for the expert assistance of Vincent Schram and Chip Dye.

\section{References}

Ali MS, Sayeski PP, Dirksen LB, Hayzer DJ, Marrero MB \& Bernstein KE 1997 Dependence on the motif YIPP for the physical association of Jak2 kinase with the intracellular carboxyl tail of the angiotensin II AT1 receptor. Journal of Biological Chemistry 272 23382-23388.

Anborgh PH, Seachrist JL, Dale LB \& Ferguson SS 2000 Receptor/beta-arrestin complex formation and the differential trafficking and resensitization of $\beta 2$-adrenergic and angiotensin II type 1A receptors. Molecular Endocrinology 14 2040-2053.

Anderson HA \& Roche PA 1998 Phosphorylation regulates the delivery of MHC class II invariant chain complexes to antigen processing compartments. Journal of Immunology 160 4850-4858.

Anderson HA, Bergstralh DT, Kawamura T, Blauvelt A \& Roche PA 1999 Phosphorylation of the invariant chain by protein kinase $\mathrm{C}$ regulates $\mathrm{MHC}$ class II trafficking to antigen-processing compartments. Journal of Immunology 163 5435-5443.

Badve S, Deshpande C, Hua Z \& Logdberg L 2002 Expression of invariant chain (CD 74) and major histocompatibility complex (MHC) class II antigens in the human fetus. Journal of Histochemistry and Cytochemistry $\mathbf{5 0}$ 473-482.

Becker-Herman S, Arie G, Medvedovsky H, Kerem A \& Shachar I 2005 $\mathrm{CD} 74$ is a member of the regulated intramembrane proteolysis-processed protein family. Molecular Biology of the Cell 16 5061-5069.

Bermak JC, Li M, Bullock C \& Zhou QY 2001 Regulation of transport of the dopamine D1 receptor by a new membrane-associated ER protein. Nature Cell Biology 3 492-498.

Bertolino P \& Rabourdin-Combe C 1996 The MHC class II-associated invariant chain: a molecule with multiple roles in MHC class II biosynthesis and antigen presentation to CD $4+\mathrm{T}$ cells. Critical Reviews of Immunology $\mathbf{1 6}$ 359-379.

Couve A, Kittler JT, Uren JM, Calver AR, Pangalos MN, Walsh FS \& Moss SJ 2001 Association of GABA(B) receptors and members of the 14-3-3 family of signaling proteins. Molecular and Cellular Neurosciences 17 317-328.

Daviet L, Lehtonen JY, Tamura K, Griese DP, Horiuchi M \& Dzau VJ 1999 Cloning and characterization of ATRAP, a novel protein that interacts with the angiotensin II type 1 receptor. Journal of Biological Chemistry 274 17058-17062.

Duvernay MT, Zhou F \& Wu G 2004 A conserved motif for the transport of $G$ protein-coupled receptors from the endoplasmic reticulum to the cell surface. Journal of Biological Chemistry 279 30741-30750.

Gaborik Z, Mihalik B, Jayadev S, Jagadeesh G, Catt KJ \& Hunyady L 1998 Requirement of membrane-proximal amino acids in the carboxyl-terminal tail for expression of the rat AT1a angiotensin receptor. FEBS Letters $\mathbf{4 2 8}$ $147-151$.

de Gasparo M, Catt KJ, Inagami T, Wright JW \& Unger T 2000 International union of pharmacology. XXIII. The angiotensin II receptors. Pharmacological Reviews 52 415-472.

Guo DF, Chenier I, Tardif V, Orlov SN \& Inagami T 2003 Type 1 angiotensin II receptor-associated protein ARAP1 binds and recycles the receptor to the plasma membrane. Biochemical and Biophysical Research Communications $3101254-1265$.

Guo DF, Tardif V, Ghelima K, Chan JS, Ingelfinger JR, Chen X \& Chenier I 2004 A novel angiotensin II type 1 receptor-associated protein induces cellular hypertrophy in rat vascular smooth muscle and renal proximal tubular cells. Journal of Biological Chemistry 279 21109-21120.
Hofmann MW, Honing S, Rodionov D, Dobberstein B, von Figura K \& Bakke O 1999 The leucine-based sorting motifs in the cytoplasmic domain of the invariant chain are recognized by the clathrin adaptors AP1 and AP2 and their medium chains. Journal of Biological Chemistry 274 36153-36158.

Hunyady L \& Catt KJ 2006 Pleiotropic AT1 receptor signaling pathways mediating physiological and pathogenic actions of angiotensin II. Molecular Endocrinology 20 953-970.

Hunyady L, Bor M, Balla T \& Catt KJ 1994 Identification of a cytoplasmic Ser-Thr-Leu motif that determines agonist-induced internalization of the AT1 angiotensin receptor. Journal of Biological Chemistry $26931378-31382$.

Hunyady L, Catt KJ, Clark AJ \& Gaborik Z 2000 Mechanisms and functions of AT(1) angiotensin receptor internalization. Regulatory Peptides 91 29-44.

Hunyady L, Baukal AJ, Gaborik Z, Olivares-Reyes JA, Bor M, Szaszak M, Lodge R, Catt KJ \& Balla T 2002 Differential PI 3-kinase dependence of early and late phases of recycling of the internalized AT1 angiotensin receptor. Journal of Cellular Biology 157 1211-1222.

Kang S, Liang L, Parker CD \& Collawn JF 1998 Structural requirements for major histocompatibility complex class II invariant chain endocytosis and lysosomal targeting. Journal of Biological Chemistry 273 20644-20652.

Kongsvik TL, Honing S, Bakke O \& Rodionov DG 2002 Mechanism of interaction between leucine-based sorting signals from the invariant chain and clathrin-associated adaptor protein complexes AP1 and AP2. Journal of Biological Chemistry 277 16484-16488.

Kuwana T, Peterson PA \& Karlsson L 1998 Exit of major histocompatibility complex class II-invariant chain p35 complexes from the endoplasmic reticulum is modulated by phosphorylation. PNAS 95 1056-1061.

Lamb CA \& Cresswell P 1992 Assembly and transport properties of invariant chain trimers and HLA-DR-invariant chain complexes. Journal of Immunology 148 3478-3482.

Lamb CA, Yewdell JW, Bennink JR \& Cresswell P 1991 Invariant chain targets HLA class II molecules to acidic endosomes containing internalized influenza virus. PNAS 88 5998-6002.

Leclerc PC, Auger-Messier M, Lanctot PM, Escher E, Leduc R \& Guillemette G 2002 A polyaromatic caveolin-binding-like motif in the cytoplasmic tail of the type 1 receptor for angiotensin II plays an important role in receptor trafficking and signaling. Endocrinology 143 4702-4710.

Leng L, Metz CN, Fang Y, Xu J, Donnelly S, Baugh J, Delohery T, Chen Y, Mitchell RA \& Bucala R 2003 MIF signal transduction initiated by binding to CD74. Journal of Experimental Medicine 197 1467-1476.

Loss GE Jr \& Sant AJ 1993 Invariant chain retains MHC class II molecules in the endocytic pathway. Journal of Immunology 150 3187-3197.

Lu M, Echeverri F \& Moyer BD 2003 Endoplasmic reticulum retention, degradation, and aggregation of olfactory G-protein coupled receptors. Traffic 4 416-433.

Lue H, Kapurniotu A, Fingerle-Rowson G, Roger T, Leng L, Thiele M, Calandra T, Bucala R \& Bernhagen J 2006 Rapid and transient activation of the ERK MAPK signalling pathway by macrophage migration inhibitory factor (MIF) and dependence on JAB1/CSN5 and Src kinase activity. Cellular Signalling 18 688-703.

McCormick PJ, Martina JA \& Bonifacino JS 2005 Involvement of clathrin and AP-2 in the trafficking of MHC class II molecules to antigenprocessing compartments. PNAS 102 7910-7915.

Michelsen K, Yuan H \& Schwappach B 2005 Hide and run. Arginine-based endoplasmic-reticulum-sorting motifs in the assembly of heteromultimeric membrane proteins. EMBO Reports 6 717-722.

Momburg F, Koch N, Moller P, Moldenhauer G, Butcher GW \& Hammerling GJ 1986 Differential expression of Ia and Ia-associated invariant chain in mouse tissues after in vivo treatment with IFN $-\gamma$. Journal of Immunology 136 940-948.

Nakatsu F, Sakuma M, Matsuo Y, Arase H, Yamasaki S, Nakamura N, Saito T \& Ohno H 2000 A Di-leucine signal in the ubiquitin moiety. Possible involvement in ubiquitination-mediated endocytosis. Journal of Biological Chemistry $27526213-26219$.

Natarajan R, Yang DC, Lanting L \& Nadler JL 2002 Key role of P38 mitogenactivated protein kinase and the lipoxygenase pathway in angiotensin II actions in H295R adrenocortical cells. Endocrine 18 295-301. 
O'Kelly I, Butler MH, Zilberberg N \& Goldstein SA 2002 Forward transport. 14-3-3 binding overcomes retention in endoplasmic reticulum by dibasic signals. Cell 111 577-588.

Olivares-Reyes JA, Smith RD, Hunyady L, Shah BH \& Catt KJ 2001 Agonistinduced signaling, desensitization, and internalization of a phosphorylation-deficient AT1A angiotensin receptor. Journal of Biological Chemistry 276 37761-37768.

Oliveira L, Costa-Neto CM, Nakaie CR, Schreier S, Shimuta SI \& Paiva AC 2007 The angiotensin II AT1 receptor structure-activity correlations in the light of rhodopsin structure. Physiological Reviews 87 565-592.

Oppermann M, Freedman NJ, Alexander RW \& Lefkowitz RJ 1996 Phosphorylation of the type $1 \mathrm{~A}$ angiotensin II receptor by G proteincoupled receptor kinases and protein kinase C. Journal of Biological Chemistry 271 13266-13272.

Qian H, Pipolo L \& Thomas WG 2001 Association of beta-Arrestin 1 with the type $1 \mathrm{~A}$ angiotensin II receptor involves phosphorylation of the receptor carboxyl terminus and correlates with receptor internalization. Molecular Endocrinology 15 1706-1719.

Roche PA, Teletski CL, Stang E, Bakke O \& Long EO 1993 Cell surface HLA-DR-invariant chain complexes are targeted to endosomes by rapid internalization. PNAS 90 8581-8585.

Sant AJ, Cullen SE \& Schwartz BD 1985 Biosynthetic relationships of the chondroitin sulfate proteoglycan with Ia and invariant chain glycoproteins. Journal of Immunology 135 416-422.

Seachrist JL, Laporte SA, Dale LB, Babwah AV, Caron MG, Anborgh PH \& Ferguson SS 2002 Rab5 association with the angiotensin II type 1A receptor promotes Rab5 GTP binding and vesicular fusion. Journal of Biological Chemistry 277 679-685.

Shibata T, Suzuki C, Ohnishi J, Murakami K \& Miyazaki H 1996 Identification of regions in the human angiotensin II receptor type 1 responsible for $\mathrm{Gi}$ and $\mathrm{Gq}$ coupling by mutagenesis study. Biochemical and Biophysical Research Communications 218 383-389.
Shivakumar BR, Wang Z, Hammond TG \& Harris RC 2005 EP24.15 interacts with the angiotensin II type I receptor and bradykinin B2 receptor. Cell Biochemistry and Function 23 195-204.

Smith RD, Hunyady L, Olivares-Reyes JA, Mihalik B, Jayadev S \& Catt KJ 1998 Agonist-induced phosphorylation of the angiotensin AT1a receptor is localized to a serine/threonine-rich region of its cytoplasmic tail. Molecular Pharmacology 54 935-941.

Thielen A, Oueslati M, Hermosilla R, Krause G, Oksche A, Rosenthal W \& Schulein R 2005 The hydrophobic amino acid residues in the membraneproximal $\mathrm{C}$ tail of the $\mathrm{G}$ protein-coupled vasopressin $\mathrm{V} 2$ receptor are necessary for transport-competent receptor folding. FEBS Letters $\mathbf{5 7 9}$ 5227-5235.

Thomas WG 1999 Regulation of angiotensin II type 1 (AT1) receptor function. Regulatory Peptides 79 9-23.

Venema RC, Ju H, Venema VJ, Schieffer B, Harp JB, Ling BN, Eaton DC \& Marrero MB 1998 Angiotensin II-induced association of phospholipase Cgamma1 with the G-protein-coupled AT1 receptor. Journal of Biological Chemistry 273 7703-7708.

Wraight CJ, van Endert P, Moller P, Lipp J, Ling NR, MacLennan IC, Koch N \& Moldenhauer G 1990 Human major histocompatibility complex class II invariant chain is expressed on the cell surface. Journal of Biological Chemistry 265 5787-5792.

Wyse BD, Prior IA, Qian H, Morrow IC, Nixon S, Muncke C, Kurzchalia TV, Thomas WG, Parton RG \& Hancock JF 2003 Caveolin interacts with the angiotensin II type 1 receptor during exocytic transport but not at the plasma membrane. Journal of Biological Chemistry 278 23738-23746.

\section{Received in final form 13 August 2008 \\ Accepted 19 August 2008 \\ Made available online as an Accepted Preprint}

21 August 2008 